\title{
MÖSSBAUER STUDY OF NANOCRYSTALLINE ALLOYS
}

\section{KOPCEWICZ}

Institute of Electronic Materials Technology, Wólczyriska 133, 01-919 Warszawa, Poland

The current status of the Mössbaner investigations of the soft magnetic nanocrystalline alloys produced by utilizing the first step of crystallization of the amorphous alloys such as $\mathrm{FeCuNbSiB}$ and $\mathrm{FeZrBCu}$ is reviewed. Conventional Mössbauer measurements allow the identification of phases formed due to annealing of the amorphous precursor and the evaluation of their relative content. The unconventional rf-Mössbauer technique, in which the rf collapse and sideband effects are employed, permits us to distinguish the magnetically soft nanocrystalline bcc-Fe phase from the magnetically harder microcrystalline Fe. Qualitative information concerning the distribution of anisotropy fields in the nanocrystalline grains can be inferred from the dependence of the rf collapsed spectra on the rf field intensity. The rf-sidebands effect reveals strong reduction of magnetostriction due to the formation of the nanocrystalline phase. The rf-Mössbaner technique provides a unique opportunity to study the microstructure and magnetic properties of each phase formed in the amorphous precursor.

PACS numbers: $76.80 .+\mathrm{y}, 75.50 . \mathrm{Kj}, 75.50 . \mathrm{Bb}, 81.40 .-\mathrm{z}$

\section{Introduction}

Nanocrystalline materials are single-phase or multiphase polycrystals, with crystal size in the nanometer range, typically 5 to $50 \mathrm{~nm}$. Such materials can be produced by various methods, e.g., compaction of nanometer-size powders, deposition techniques or by crystallization of amorphous precursors. Due to very small dimensions nanocrystalline materials contain large volume fraction of grain and interphase boundaries which may significantly alter physical, chemical, and mechanical properties as compared to the conventional coarse-grained polycrystalline materials. Nanocrystalline materials may reveal improved hardness and ductility, reduced elastic modulus, enhanced diffusivity, enhanced thermal expansion, and superior soft or hard magnetic properties. Therefore nanocrystalline materials provide us an excellent opportunity to study the artificial magnetic materials whose properties are governed by reduced dimensionality in the nanometer length scale. With continuing demand for increasingly efficient soft magnetic materials 
for technological applications the theoretical and experimental effort aimed at the development of novel magnetic materials has increased dramatically in recent years.

Several years ago a new class of soft magnetic materials, important for technological applications and interesting from the point of view of basic research, has been developed. It has been reported that the bcc structure with a nanoscale grain size can be formed in amorphous FeSiB-based alloys containing $\mathrm{Cu}$ and $\mathrm{Nb}$ by utilizing the first stage of the crystallization process. The first experiments performed by Yoshizawa et al. [1] for the $\mathrm{Fe}_{73.5} \mathrm{Cu}_{1} \mathrm{Nb}_{3} \mathrm{Si}_{13.5} \mathrm{~B}_{9}$ alloy have shown that annealing the amorphous alloy at temperatures between $520^{\circ} \mathrm{C}$ and $650^{\circ} \mathrm{C}$ leads to the formation of the nanocrystalline bcc $\mathrm{Fe}(\mathrm{Si})$ phase witl a well defined homogeneous grains, with a typical size of $10-15 \mathrm{~nm}$, embedi 1 in the retained amoiphous structure. The formation of the bcc- $\mathrm{Fe}(\mathrm{Si})$ nanostructure in the $\mathrm{FeCuNbSiB}$ system was explained by a combination of an increased nucleation rate of the bcc phase resulting from the immiscibility of $\mathrm{Cu}$ to $\mathrm{Fe}$ and a reduced crystal growth rate due to the small diffusivity of $\mathrm{Nb}$ in $\mathrm{Fe}$. This nanocrystalline phase reveals excellent soft magnetic properties: low coercive field, high saturation magnetization, high permeability and low magnetostriction. However, the saturation magnetization is lower than that typical of the Fe-metalloid amorphous alloys, mainly because of the lower $\mathrm{Fe}$ concentration related to the addition of $\mathrm{Nb}$ and $\mathrm{Cu}$. Excellent soft magnetic properties are attributed to the decrease in the effective magnetic anisotropy which is randomly averaged by the exchange interaction and is related to the refinement of the grain size $[2,3]$. Since the first experiments of Yoshizawa et al. [1] considerable experimental effort has been devoted to the study of structural and magnetic properties of $\mathrm{FeCuNbSiB}$ alloys [4-8].

Recently, a similar phenomenon was observed in simpler ternary $\mathrm{Fe}-\mathrm{M}-\mathrm{B}$ alloys (M: Zr, $\mathrm{Nb}, \mathrm{Hf}, \mathrm{Ta}$ ) [9-13] which reveal magnetic properties superior to those of $\mathrm{FeCuNbSiB}$ alloys (higher saturation magnetization and permeability). Annealing of the amorphous precursor causes the formation of nanoscale grains of the bcc Fe which exhibit high saturation magnetization (1.7 T). Addition of $1-2 \% \mathrm{Cu}$ causes, as before, a decrease in the crystallization temperature and an increase in the nucleation rate. However, the $\mathrm{Fe}$-rich $\mathrm{Fe}-\mathrm{Zr}$ and $\mathrm{Fe}-\mathrm{Hf}$ alloys exhibit an invar effect accompanied by the decrease in the Curie temperature which leads to the decrease in magnetization at room temperature. A nanostructure consisting of metastable bcc grains formed in the $\mathrm{FeZrB}$ or $\mathrm{FeHfB}$ systems by crystallization of the amorphous phase is expected to exhibit high saturation magnetization $[14,15]$. Furthermore, the solid solutions such as $\mathrm{Fe}-\mathrm{Zr}$ and $\mathrm{Fe}-\mathrm{Hf}$ supersaturated phases reveal very small magnetostriction $\left(\approx 1 \times 10^{-6}\right)[16]$.

Structural properties of nanocrystalline alloys were studied by various methods including differential scanning calorimetry (DSC), differential thermal analysis (DTA) (crystallization temperature), X-ray diffraction (XRD), Mössbauer spectroscopy (for phase identification) and transmission electron microscopy (TEM) (for determination of the grain size), while the magnetic properties were usually determined by such conventional instruments as the vibrating sample magnetometer (VSM) and a DC B-H loop tracer and vector impedance analyser. 
Nanocrystalline alloys exhibiting excellent soft magnetic properties are promising candidates for wide applications in technology. Not only the saturation magnetization and permeability exceed those of most conventional materials (e.g., ferrites, Si-steels, Fe-based amorphous alloys) but remanence is high, coercivity is very small, magnetostriction is almost vanishing, and core losses in a wide frequency range are much smaller as compared with Si-steels or even Fe-based amorphous alloys [14]. Such a combination of magnetic properties is very favourable for technical applications in power transformers, data communication components, pulsed transformers, choke coils, magnetic heads, sensors, and magnetic shielding.

Soft magnetic properties of nanocrystalline alloys are usually interpreted in terms of the random anisotropy model. Herzer [2, 3] has successfully applied the Alben-Becker-Chi model [17] to account for the dependence of coercivity on the size of the nanograins. However, this model is valid for a single phase system in which the exchange interaction between first-neighbour magnetic moments involves only one constant. In the case of nanocrystalline alloys there are three exchange constants corresponding to interactions between adjacent atoms of crystallites, adjacent atoms of the amorphous matrix and adjacent atoms through the crystallite-amorphous interface. The simplified Herzer model successfully accounts for the main features of the coercivity vs. grain size but fails to explain the recently reported magnetic hardening effect observed at the early stages of crystallization to a nanoscale structure. The latter effect was recently explained by Hernando et al. [18] who generalized the random anisotropy model to two magnetic phase system and have shown that the exchange interaction between crystallites is transmitted through the amorphous matrix. This exchange is effective only if there is sufficient volume fraction of nanograins and when the residual amorphous matrix is ferromagnetic. At low crystallized fraction or at temperatures close to or exceeding the Curie temperature of the amorphous matrix the system behaves as an assembly of isolated particles in which the intercrystallite exchange interaction is too weak, thus leading to the dramatic increase in coercivity $[18,19]$.

Mössbauer spectroscopy was successfully used for identification of the phases formed due to annealing of the amorphous precursors both of the FeCuNbSiB [20-25] and $\mathrm{Fe}-\mathrm{M}-\mathrm{B}$ type alloys [26-33]. However, information regarding the grain size cannot be obtained from the conventional Mössbauer measurements and must be obtained either by the TEM or XRD method. Another method that can provide microstructural information is small-angle X-ray scattering (SAXS) and this technique has been applied recently to the nanocrystalline alloys of interest here [31, 32]:

The crystallization behaviour of amorphous $\mathrm{FeCuNbSiB}$ alloys was studied in great detail [21, 24-26]. The analysis of the Mössbauer spectra allowed the identification of the nanocrystalline phase as the bcc-Fe(Si). The dependence of the formation of this phase on the thermal treatment (annealing temperature and time) was determined $[20,25]$. New ternary FeMB alloys attracted also a lot of attention. In particular the structural properties of the nanocrystalline $\mathrm{FeZrB}(\mathrm{Cu})$ system was investigated [26-33]. Great effort was devoted to the interpretation of the properties of the interface regions, separating bcc grains from the amorphous matrix. Miglierini et al. [2, 30] performed a systematic study of this problem. The crystallization kinetics was studied for FeCuNbSiB alloy [34]. The Mössbauer mea- 
surements supplemented by transmission electron microscopy and electron diffraction studies performed for samples annealed for short times have clearly shown that in order to form good soft magnetic nanostructure, short time annealing (15-30 s) at temperatures higher $\left(650^{\circ} \mathrm{C}\right)$ than normally used in conventional 1 hour anneals $\left(550-600^{\circ} \mathrm{C}\right)$ is sufficient.

Conventional Mössbauer spectroscopy allow identification and estimation of the relative abundance of phases formed due to annealing of the amorphous precursor but do not provide information regarding the magnetic anisotropy, magnetostriction, and size of the grains. Recently the unconventional Mössbauer technique which makes use of the effects induced by an external magnetic radio-frequency field applied to the material investigated was used to elucidate the properties of nanocrystalline $\mathrm{FeCuNbSiB}[35]$ and $\mathrm{FeZrB}(\mathrm{Cu})$ alloys $[31-33,36,37]$. Further discussion of the Mössbauer investigations of the nanocrystalline alloys will be devoted mainly to our results obtained recently for $\mathrm{FeZrB}(\mathrm{Cu})$ alloys in which various Mössbauer techniques (conventional transmission, conversion electron Mössbauer spectroscopy - CEMS and rf-Mössbauer) were used. The Mössbauer measurements were supplemented by complementary techniques including DSC, XRD, and SAXS. The detailed discussion of these investigations is given in Refs. [31-33].

\section{Experiments}

The $\mathrm{Fe}_{93-x-y} \mathrm{Zr}_{7} \mathrm{~B}_{x} \mathrm{Cu}_{y}(x=6,8,12 ; y=0,2)$ and $\mathrm{Fe}_{89} \mathrm{Zr}_{7} \mathrm{~B}_{4}$ amorphous alloys were prepared by the melt spinning technique in protective $\mathrm{He}$ atmosphere. The ribbons were $4 \mathrm{~mm}$ wide and about $20 \mu \mathrm{m}$ thick. In order to obtain the nanocrystalline phase the amorphous ribbons with $x=6,8,12$ and $y=0,2$ were annealed in an Ar atmosphere for 1 hour at temperatures $T_{\mathrm{A}}=430,500,550,600$ and $780^{\circ} \mathrm{C}$; and the amorphous $\mathrm{Fe}_{89} \mathrm{Zr}_{7} \mathrm{~B}_{4}$ alloy at $T_{\mathrm{A}}=450,475,500,550$ and $650^{\circ} \mathrm{C}$. The DSC measurements were performed to establish the first and second crystallization peaks. The heating rate was $20 \mathrm{~K} / \mathrm{min}$. A Perkin-Elmer DSC-7 calorimeter was used.

The main characterization technique used was the Mössbauer spectroscopy. Both the conventional transmission geometry method and the specialized if-Mössbauer technique were used. Conventional Mössbauer measurements were performed for the as-quenched and annealed samples before and after if exposure. The Mössbauer measurements were performed with a conventional constant acceleration spectrometer with a ${ }^{57} \mathrm{Co}-\mathrm{in}-\mathrm{Rh}$ source with an activity of about $20 \mathrm{mCi}$. The isomer shift data are given with respect to the $\alpha$-Fe standard.

The unconventional $\mathrm{xf}$-Mössbauer measurements were performed during exposure of the samples to a magnetic radio-frequency field ranging from 0 to $20 \mathrm{Oe}$ at $60.8 \mathrm{MHz}$, a frequency about three times higher than the Larmor frequency. The samples suitable for rf experiments covered an area of $14 \mathrm{~mm} \times 16 \mathrm{~mm}$. They were placed inside the coil of an rf power generator and measured in transmission geometry during if exposure. The rf field was applied in the plane of the sample, which played a role of a stationary absorber in the Mössbauer experiments. To avoid excessive rf heating the sample holder was water cooled, in the same way as in earlier experiments [31-37]. 
The Mössbauer spectra recorded in the absence of the rf field were fitted using the NORMOS program [38]. The spectra of the amorphous alloys in which no crystalline phases were formed were fitted with the hyperfine field distribution, $P(H)$, method. The histogram method of Hesse and Rübartsch [39] with constraints introduced by LeCaer and Dubois [40] was used. The shape of the $P(H)$ distribution and the average value of the hyperfine field $\left\langle H_{\mathrm{hf}}\right\rangle$ and isomer shift were determined. In order to account for the apparent asymmetry of the hyperfine split spectra, a linear correlation between the isomer shift, $\delta$, and the hyperfine field, $H_{\mathrm{hf}}$, was assumed. The spectra of the samples in which the crystalline phases were formed were fitted with a superposition of the $P(H)$ distribution and discrete values of the hyperfine parameters ( $H_{\mathrm{hf}}, \delta$, and quadrupole splitting, QS) characteristic of a given crystalline phase.

$\mathrm{X}$-ray diffraction was used for characterization of the annealed samples and for monitoring the formation of the bcc phase as a function of annealing temperature. The XRD measurements were performed at room temperature using $\mathrm{Cu} K_{\alpha}$ radiation.

The same samples were also examined by small-angle X-ray scattering technique $[31,32]$.

\section{Results and discussion}

\subsection{DSC measurements}

The crystallization behaviour of $\mathrm{Fe}_{93-x-y} \mathrm{Zr}_{7} \mathrm{~B}_{x} \mathrm{Cu}_{y}$ alloys was studied by DSC. All alloys crystallized through two steps as revealed by two exothermic peaks in DSC curves (onset temperatures $T_{x_{1}}$ and $T_{x_{2}}$ are indicated in Fig. 1). The crystallization temperatures depend on the boron content and for a given boron level decrease markedly upon addition of $2 \% \mathrm{Cu}$. The first stage with the crystallization temperature $\left(T_{x_{1}}\right)$ corresponds to the structural transformation from the amorphous to the nanoscale bcc phase. The second exothermic peak $\left(T_{x_{2}}\right)$ reflects the transformation of the remaining amorphous phase to a mixture of FeZr compounds and microcrystalline $\alpha$-Fe. The nanocrystalline bcc Fe phase can be formed in the temperature range between $T_{x_{1}}$ and $T_{x_{2}}$. The $2 \% \mathrm{Cu}$ content not only decreases the $T_{x_{1}}$ temperature but also extends the temperature range between $T_{x_{1}}$ and $T_{x_{2}}$ (Fig. 1).

\subsection{XRD results}

The X-ray diffraction measurements were performed for all alloys in various stages of crystallization. By annealing the $\mathrm{FeZrB}(\mathrm{Cu})$ alloys at $550^{\circ} \mathrm{C}$ and $600^{\circ} \mathrm{C}$ the bcc-Fe phase is formed as revealed by the appearance of distinct diffraction peaks whose positions agree well with the $\alpha$-Fe phase. Although not clear in the $\mathrm{XRD}$ patterns, the amorphous phase remains dominant after the $550^{\circ} \mathrm{C}$ and $600^{\circ} \mathrm{C}$ anneals as shown by the Mössbauer results below. The linewidths of the (110) peaks in the $600^{\circ} \mathrm{C}$ patterns were used to estimate an average bcc-Fe grain size via the Scherrer formula. For example, for $\mathrm{Fe}_{81} \mathrm{Zr}_{7} \mathrm{~B}_{12}$ and $\mathrm{Fe}_{79} \mathrm{Zr}_{7} \mathrm{~B}_{12} \mathrm{Cu}_{2}$ alloys the values of 21 and $9 \mathrm{~nm}$ were found, respectively. Thus the $\mathrm{Cu}$ addition has clearly promoted the formation of a smaller bcc-Fe grain size and prevented the formation of other crystalline phases at the same annealing temperatures [31]. 


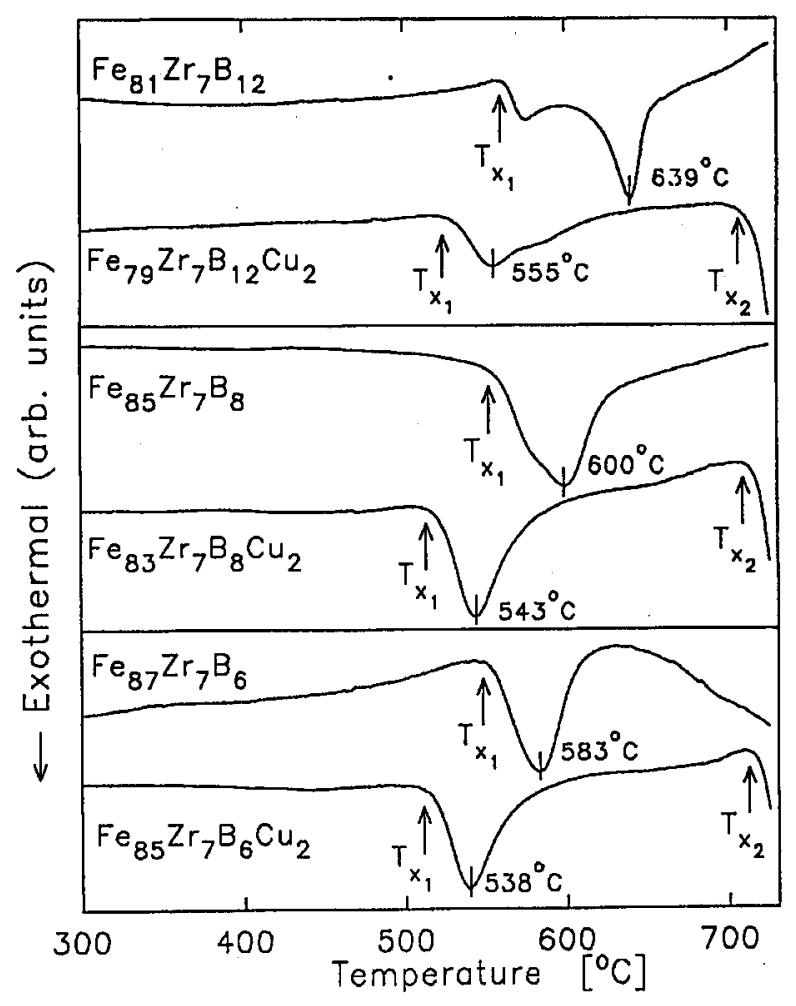

Fig. 1. The DSC curves for $\mathrm{Fe}_{93-x-y} \mathrm{Zr}_{7} \mathrm{~B}_{x} \mathrm{Cu}_{y}$ alloys.

At $780^{\circ} \mathrm{C}$ both alloys crystallized completely. The $\alpha$-Fe phase dominates in the FeZrB alloy. In the case of the FeZrBCu alloy clear diffraction peaks corresponding to $\mathrm{Cu}$ appeared in addition to the $\alpha$-Fe pattern. These XRD results are in good agreement with those reported in the literature for various $\mathrm{FeZrBCu}$ alloys $[9,41]$.

\subsection{Conventional Mössbauer studies}

The Mössbauer measurements clearly show the annealing-induced changes in the microstructure of amorphous $\mathrm{FeZr} \mathrm{B}(\mathrm{Cu})$ alloys. All $\mathrm{Fe}_{93-x-y} \mathrm{Zr}_{7} \mathrm{~B}_{x} \mathrm{Cu}_{y}(x=6$, 8,$12 ; y=0,2$ ) alloys are fully amorphous in the as-quenched state. Annealing at $T_{\mathrm{A}}=430^{\circ} \mathrm{C}$ does not induce any detectable crystallization, in agreement with the DSC results. Only the alloy with $x=12$ and $y=0$ does not start to crystallize at $T_{\mathrm{A}}=500^{\circ} \mathrm{C}$. In all other alloys annealing at $T_{\mathrm{A}}=500^{\circ} \mathrm{C}$ induces the crystallization and the bcc-Fe phase appears. As an example the results for the $\mathrm{Fe}_{85} \mathrm{Zr}_{7} \mathrm{~B}_{8}$ and $\mathrm{Fe}_{83} \mathrm{Zr}_{7} \mathrm{~B}_{8} \mathrm{Cu}_{2}$ alloys in the as-quenched state and after annealing for $1 \mathrm{~h}$ at $T_{\mathrm{A}}=$ $430,500,550$ and $600^{\circ} \mathrm{C}[32]$ are shown in Figs. 2 and 3, respectively. As can be seen from Figs. $2 a$ and $3 a$ the spectra of the as-quenched alloys are typical of the fully amorphous.alloys and consist of the broadened Zeeman sextet. The broadening is due to the variety of local atomic arrangements in the amorphous state. The 


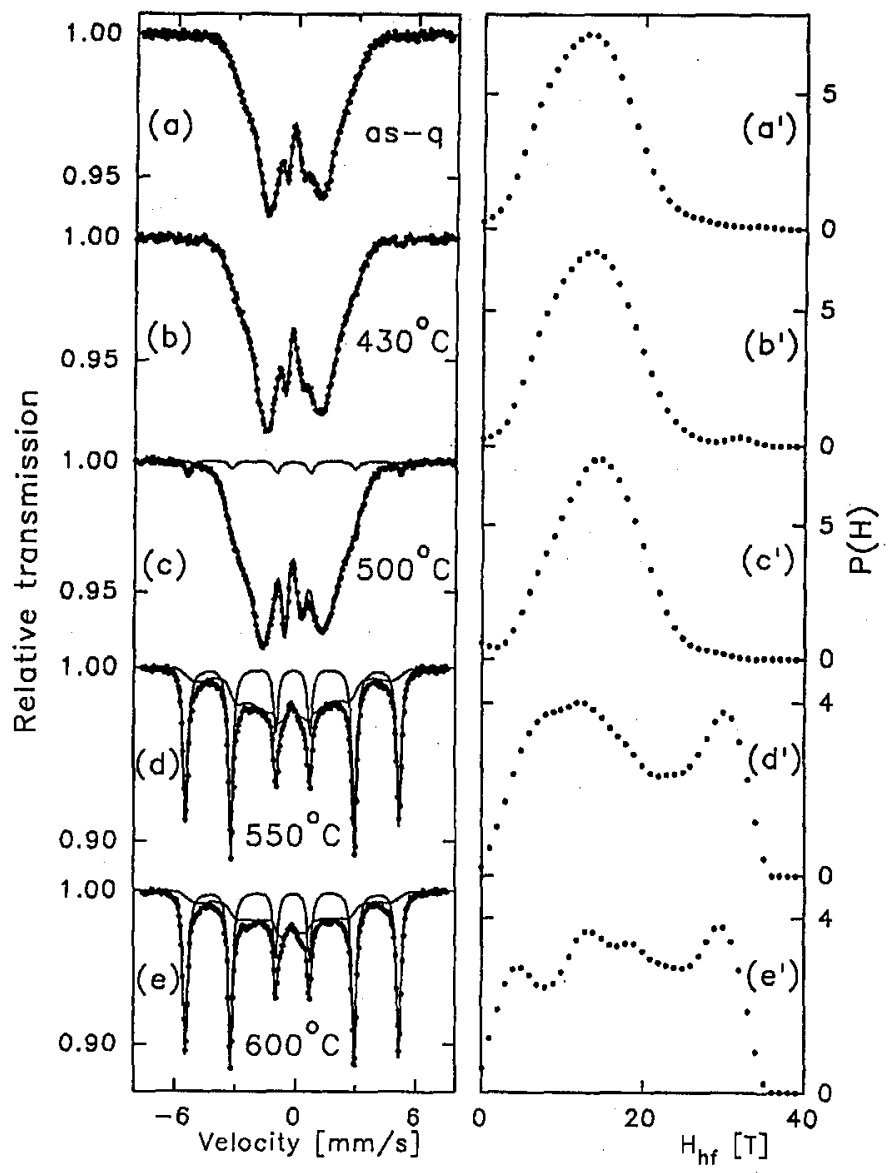

Fig. 2. The Mössbauer spectra and corresponding $P(H)$ distributions for the $\mathrm{Fe}_{85} \mathrm{Z}_{7} \mathrm{~B}_{8}$ alloy in the as-quenched state $\left[(a)\right.$ and $\left.\left(a^{\prime}\right)\right]$ and after annealing at $430-600^{\circ} \mathrm{C}[(\mathrm{b})-(\mathrm{e})$ and $\left.\left(\mathrm{b}^{\prime}\right)-\left(\mathrm{e}^{\prime}\right)\right]$.

$P(H)$ distributions, extracted from the spectra of the as-quenched alloys, shown in Figs. 2a' and $3 \mathrm{a}^{\prime}$, consist of a single broad bell-like peak. After annealing at $430^{\circ} \mathrm{C}$ the samples are still completely amorphous (Figs. $2 \mathrm{~b}$ and $3 \mathrm{~b}$ ).

Annealing at $500^{\circ} \mathrm{C}$ induces the onset of crystallization in both alloys. The six-line spectral component with sharp lines and the hyperfine field of $32.9 \mathrm{~T}$ and isomer shift $\delta=0.00 \mathrm{~mm} / \mathrm{s}$, characteristic of the bcc-Fe phase, appears in the spectra in Figs. $2 \mathrm{c}$ and $3 \mathrm{c}$. The spectral contribution of the bcc-Fe sextet is much larger for the $\mathrm{Fe}_{83} \mathrm{Zr}_{7} \mathrm{~B}_{8} \mathrm{Cu}_{2}$ alloy than for the $\mathrm{Fe}_{85} \mathrm{Zr}_{7} \mathrm{~B}_{8}$ one. The $P(H)$ distribution is only slightly affected by the formation of the bcc-Fe phase in the FeZrB alloy (Fig. 2 $c^{\prime}$ ). However, in the Cu-containing alloy a second peak with $\left\langle H_{\mathrm{hf}}\right\rangle \approx 29 \mathrm{~T}$ appears in the $P(H)$ distribution, and the peak corresponding to the remaining amorphous phase is shifted towards higher $H_{\mathrm{hf}}$ values (Fig. $3 \mathrm{c}^{\prime}$ ). The change of the shape of the $P(H)$ distribution reveals that the formation of the 

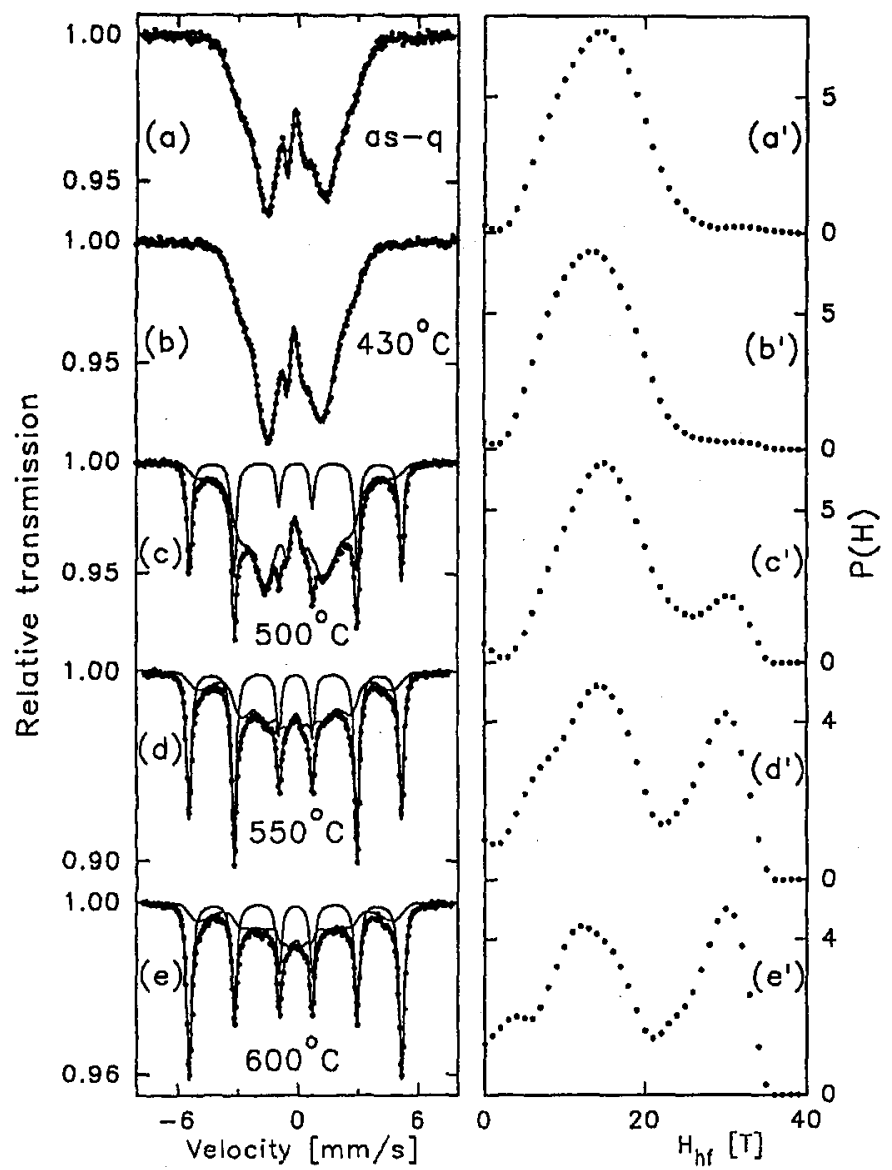

Fig. 3. The Mössbauer spectra and corresponding $P(H)$ distributions for the $\mathrm{Fe}_{83} \mathrm{Zr}_{7} \mathrm{~B}_{8} \mathrm{Cu}_{2}$ alloy in the as-quenched state $\left[(\mathrm{a})\right.$ and $\left.\left(\mathrm{a}^{\prime}\right)\right]$ and after annealing at $430-600^{\circ} \mathrm{C}\left[(\mathrm{b})-(\mathrm{e})\right.$ and $\left.\left(\mathrm{b}^{\prime}\right)-\left(\mathrm{e}^{\prime}\right)\right]$.

bcc-Fe phase markedly affects the retained amorphous structure; the iron content is decreased and thus the Curie temperature raised, implying a larger hyperfine field. It is known from the literature that the decrease in iron content in amorphous $\mathrm{FeZrB}$ alloys causes the increase in $T_{\mathrm{C}}$ [42].

Annealing at $550^{\circ} \mathrm{C}$ (Figs. 2d, 3d) and $600^{\circ} \mathrm{C}$ (Figs. 2e, 3e) drastically increases the spectral contributions corresponding to the bcc-Fe phase. The Zeeman sextet with sharp lines dominates in the spectra (Figs. 2d, 2e, 3d, 3e). The shape of the $P(H)$ distribution changes markedly. The first peak corresponding to the remaining amorphous phase is broadened, and the second peak, at $\left\langle H_{\mathrm{hf}}\right\rangle \approx 28 \mathrm{~T}$, increases significantly (Figs. $2 \mathrm{~d}^{\prime}, 2 \mathrm{e}^{\prime}, 3 \mathrm{~d}^{\prime}, 3 \mathrm{e}^{\prime}$ ). The origin of the latter is related to $\mathrm{Fe}$ atoms at the grain boundaries between the bcc-Fe grains and the amorphous matrix. The spectral contribution of the grain boundary component (the relative area of the second peak in $P(H$.$\left.) , Figs. 2 \mathrm{~d}^{\prime}, 2 \mathrm{e}^{\prime}, 3 \mathrm{c}^{\prime}-3 \mathrm{e}^{\prime}\right)$ increases with developing crystallization and increased abundance of the bcc-Fe grains, as seen in the 
Mössbauer spectra in Figs. 2d, 2e, 3c-3e. Thus, with the increasing number of bcc-Fe nanocrystals, corresponding increases are seen in the contribution due to the boundary regions between nanocrystals and the amorphous matrix in which those grains are embedded.

Annealing the alloys at temperatures exceeding $T_{x_{2}}$ (Fig. 1) causes complete crystallization of the amorphous phase. The Mössbauer spectra of all $\mathrm{Fe}_{93-x-y} \mathrm{Zr}_{7} \mathrm{~B}_{x} \mathrm{Cu}_{y}$ alloys annealed at $T_{\mathrm{A}}=780^{\circ} \mathrm{C}$ consist of a single spectral component characteristic of the $\alpha$-Fe phase. Thus, the Fe atoms are completely separated from other alloy components.

The crystallization behaviour of alloys with $x=6$ and $y=0$ or 2 proceeds in almost exactly the same way. The same bcc-Fe phase appears at the same temperatures, and its spectral contribution increases with increasing $T_{\mathrm{A}}$ in a similar way as in Figs. 2 and $3(x=8)$. The alloys with higher boron content $(x=12)$ crystallize also in a similar way, only that in the alloy with $y=0$, for which the $T_{x_{1}}$ temperature is the highest, as revealed by DSC measurements (Fig. 1), the crystallization of the bcc-Fe phase is much less efficient at all temperatures $\left(T_{\mathrm{A}} \leq 600^{\circ} \mathrm{C}\right)$. In the $\mathrm{Fe}_{79} \mathrm{Zr}_{7} \mathrm{~B}_{12} \mathrm{Cu}_{2}$ alloy annealed at $T_{\mathrm{A}}=550^{\circ} \mathrm{C}$ and $600^{\circ} \mathrm{C} \mathrm{a}$ small spectral component due to the fcc-Fe phase was detected [31].

The relative atomic fractions of the bcc-Fe phase determined from the relative area of the spectral component with the $H_{\mathrm{hf}}=32.95 \mathrm{~T}$ and $\delta=0.00 \mathrm{~mm} / \mathrm{s}$ observed in the Mössbauer spectra of all alloy compositions vs. annealing temperature are shown in Fig. 4. As can be seen, the increase in boron content increases the $T_{x_{1}}$ temperature resulting in the enhanced thermal stability of the amorphous phase. The relative abundance of the bcc-Fe phase increases with decreasing boron content for a given $T_{\mathrm{A}}$ above $430^{\circ} \mathrm{C}$ (Figs. $4 \mathrm{a}-4 \mathrm{~d}$ ). The presence of $2 \% \mathrm{Cu}$ decreases the $T_{x_{1}}$ temperature and dramatically promotes the precipitation of the bcc-Fe phase. This effect is clearly seen especially for temperatures close to $T_{x_{1}}$ (e.g. $500^{\circ} \mathrm{C}$ ), Figs. $4 \mathrm{~b}, 4 \mathrm{c}$. The highest relative amount of the bcc-Fe phase formed at $600^{\circ} \mathrm{C}$ is observed for low boron content $\left(x=6\right.$, Fig. 4 c) and at $650^{\circ} \mathrm{C}$ for $\mathrm{Fe}_{89} \mathrm{Zr}_{7} \mathrm{~B}_{4}$ (Fig. 4d).

All the alloys in the as-quenched state discussed above are ferromagnetic at room temperature. The $\mathrm{Fe}_{89} \mathrm{Zr}_{7} \mathrm{~B}_{4}$ alloy is different in this respect; its Curie temperature is lower than room temperature. Hence, this case is unique in this set of alloys because the ferromagnetic nanocrystalline bcc-Fe phase is formed in the paramagnetic amorphous matrix by annealing. Due to the formation of the bcc-Fe phase the content of $\mathrm{Fe}$ in the retained amorphous phase decreases thereby causing the amorphous phase to become magnetically ordered at room temperature ( $T_{\mathrm{C}}$ increases with decreasing Fe content in amorphous FeZrB alloys [42]). This effect is clearly seen in Fig. 5. The Mössbauer spectrum of the as-quenched $\mathrm{Fe}_{89} \mathrm{Zr}_{7} \mathrm{~B}_{4}$ alloy consists almost exclusively of the broadened quadrupole doublet (Fig. 5a). Annealing at $T_{\mathrm{A}}=475^{\circ} \mathrm{C}$ causes the formation of the bcc-Fe phase, as seen by the appearance of the Zeeman sextet (Fig. 5b) with a spectral contribution of about $10 \%$. This component drastically increases with increasing annealing temperature (Figs. 5c-5e). Very interesting is the change of the structure of the retained amorphous phase. At $T_{\mathrm{A}}=475^{\circ} \mathrm{C}$ the central part of the spectrum broadens considerably and its shape changes. The amorphous matrix becomes magnetic 


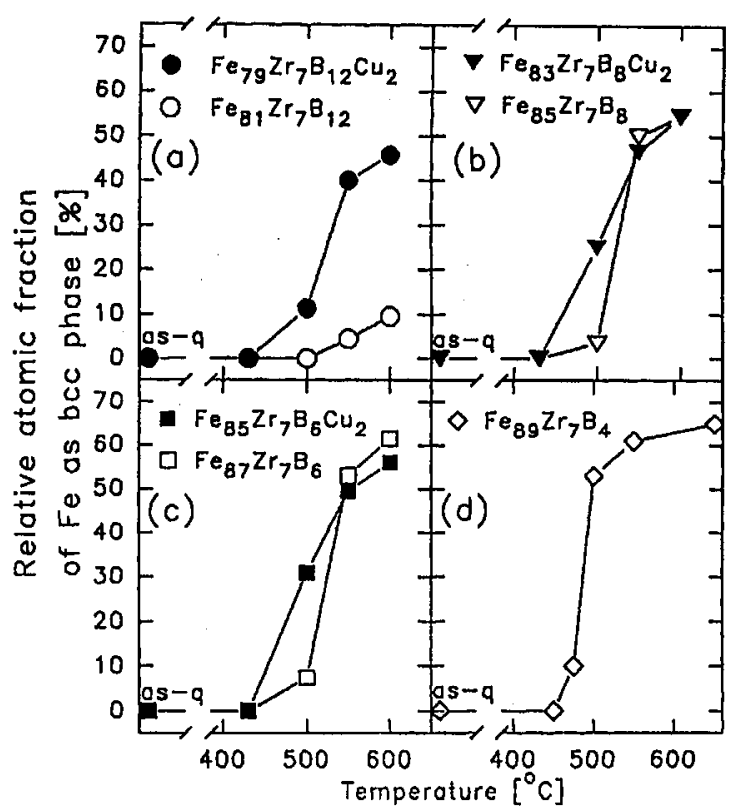

Fig. 4. The relative abundance of the bcc-Fe phase determined from the conventional Mössbauer measurements.

and the hyperfine field distribution $P(H)$ extracted from the spectrum in Fig. 5b consists of a strong peak at low $H_{\mathrm{hf}}$ values $\left(\left\langle H_{\mathrm{hf}}\right\rangle \approx 3 \mathrm{~T}\right)$ and a smaller but much wider peak at about $13 \mathrm{~T}$ (Fig. $5 \mathrm{~b}^{\prime}$ ). Such a shape of the $P(H)$ distribution suggests that the composition of the amorphous phase is strongly inhomogeneous. Higher annealing temperature strongly promotes crystallization and the spectral contribution of the bcc-Fe sextet dramatically increases (Figs. 5c-5e, and Fig. 4d). The $P(H)$ distributions related to the amorphous matrix clearly reveal the complex structure. At $T_{\mathrm{A}}=500^{\circ} \mathrm{C}\left(\mathrm{Fig} .5 \mathrm{c}^{\prime}\right)$ the main peak in $P(H)$ is shifted towards larger $H_{\mathrm{hf}}$ due to the decrease in Fe content in the amorphous phase and is observed at $H_{\mathrm{hf}} \approx 13 \mathrm{~T}$. The second peak at $H_{\mathrm{hf}} \approx 31 \mathrm{~T}$ is most probably related to the grain boundary regions. At $T_{\mathrm{A}}=550^{\circ} \mathrm{C}$ the first peak in the $P(H)$ distribution splits into two clear peaks suggesting strong composition modulation in the amorphous phase (Fig. $5 \mathrm{~d}^{\prime}$ ). This effect is even stronger at $T_{\mathrm{A}}=650^{\circ} \mathrm{C}$ (Fig. $5 \mathrm{e}^{\prime}$ ). The average hyperfine field in $P(H)$ is clearly related to the iron content in the amorphous phase, and the lower Fe content with increasing $T_{\mathrm{A}}$ leads to the larger values of $H_{\mathrm{hf}}$. The contribution of the grain boundary component (the peak at $H_{\mathrm{hf}}=30-31 \mathrm{~T}$ in $P(H)$ ) increases with increasing contribution of the bcc-Fe phase, in agreement with increasing numbers of nanoparticles.

The conventional Mössbauer measurements allow the identification of the crystallization product as the bcc-Fe phase and the determination of the relative abundance of $\mathrm{Fe}$-containing phases vs. annealing temperature and alloy composition. It is possible also to follow the changes of the structure of the amorphous phase due to the formation of the bcc-Fe phase. Taking into account the DSC results we can expect that the bcc-Fe phase formed at $500^{\circ} \mathrm{C} \leq T_{\mathrm{A}} \leq 650^{\circ} \mathrm{C}$ is 


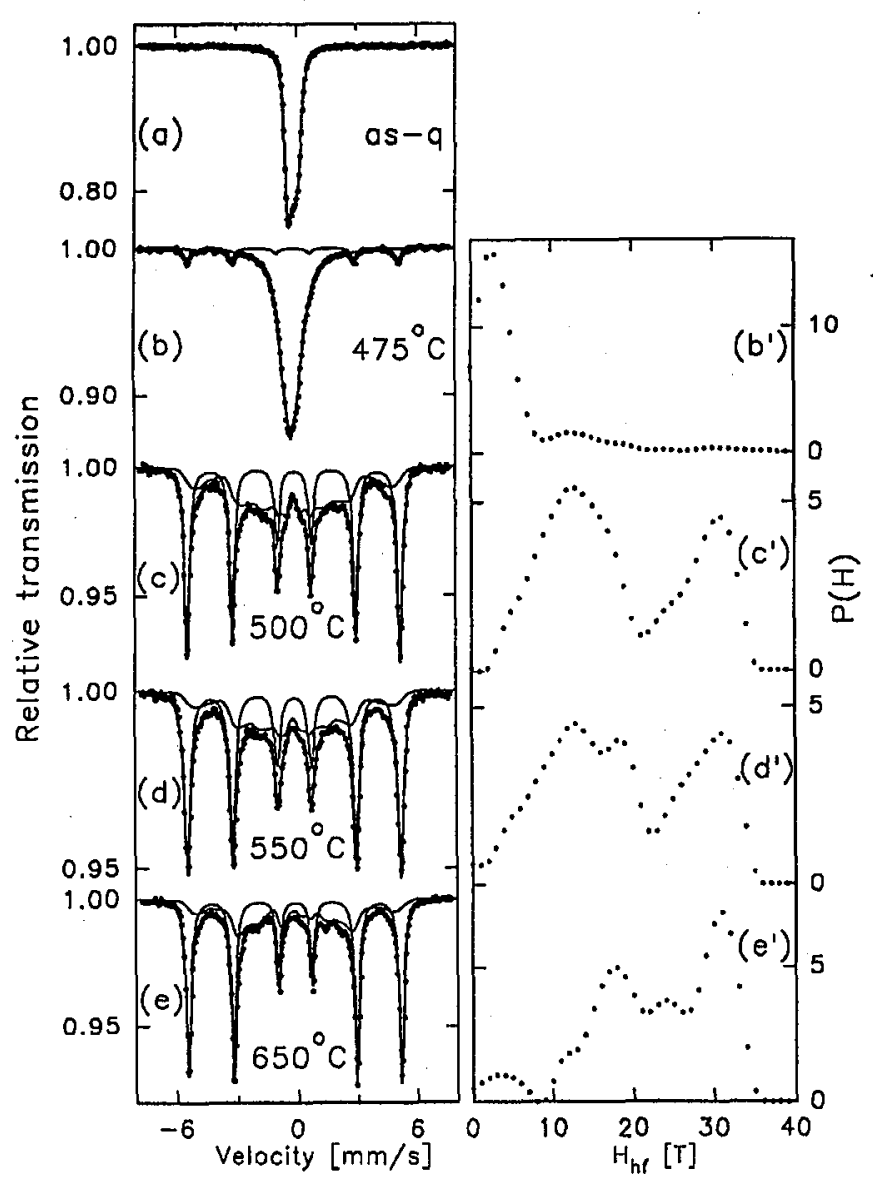

Fig. 5. The Mössbauer spectra and corresponding $P(H)$ distributions for the $\mathrm{Fe}_{89} \mathrm{Zr}_{7} \mathrm{~B}_{4}$ alloy in the as-quenched state (a) and after annealing at $470-650^{\circ} \mathrm{C}[(\mathrm{b})-(\mathrm{e})$ and $\left.\left(b^{\prime}\right)-\left(e^{\prime}\right)\right]$.

nanocrystalline. However, the conventional Mössbauer technique does not permit verification of the grain size or the magnetic properties of the nanoscale Fe grains, such as small magnetic anisotropy and vanishing magnetostriction.

\subsection{Rf-Mössbauer studies}

The unconventional technique which combines the Mössbauer effect with the phenomena induced by an external radio-frequency magnetic field (rf collapse and rf side band effects) was applied for the first time for the study of amorphous and nanocrystalline $\mathrm{FeCuNbSiB}$ alloys [35]. The $\mathrm{rf}$-Mössbauer experiment allowed us to distinguish the nanocrystalline $\mathrm{Fe}_{3} \mathrm{Si}$ phase from the microcrystalline phases formed in the course of annealing. The rf-Mössbauer technique makes use of the collapse of the magnetic hyperfine splitting due to fast magnetization reversal induced by an external radio-frequency magnetic field [43-45]. If the frequency of 
the rf field is larger than the Larmor precession frequency and the rf field is sufficiently strong to overcome local magnetic anisotropy then the magnetic hyperfine field is averaged to zero at the Mössbauer nuclei. The rf-collapsed spectra, which appear in place of the magnetically split six-line pattern, consist of a quadrupole doublet or a single line only, in spite of the sample being in the ferromagnetic state. The rf collapse effect is very sensitive to even small changes of the magnetic anisotropy and occurs only in soft ferromagnets. Thus one can distinguish the very soft nanocrystalline phase from the magnetically harder microcrystalline ones. The second if induced effect, the rf side bands, originates from the if field induced vibrations of atoms via magneto-acoustic coupling, which is magnetostriction [43, 46-48]. The latter causes the frequency of the Mössbauer gamma radiation to be modulated due to the Doppler effect and a set of side band lines appears in the spectra of ferromagnetic, magnetostrictive materials. The of side band effect thus allows the study of magnetostriction properties, e.g. the decrease in magnetostriction due to the formation of nanocrystalline grains. The rf side bands disappear when magnetostriction vanishes. The rf collapse and side band effects are reviewed extensively elsewhere [43, 49-51]. The rf-Mössbauer technique was recently successfully applied to the study of $\mathrm{FeCuNbSiB}[52,53]$ and $\mathrm{FeZrBCu}$ alloys [31-33, 36, 37].

As an example of the application of the rf-Mössbauer technique the results obtained for the $\mathrm{Fe}_{81} \mathrm{Zr}_{7} \mathrm{~B}_{12}$ and $\mathrm{Fe}_{79} \mathrm{Zr}_{7} \mathrm{~B}_{12} \mathrm{Cu}_{2}$ alloys will be discussed here [31]. The Mössbauer spectra of these alloys in the as-quenched and annealed state were measured during exposure to the magnetic if field of $20 \mathrm{Oe}$ at $60.8 \mathrm{MHz}$. Typical results are shown in Figs. $6 \mathrm{a}^{\prime}-6 \mathrm{e}^{\prime}$ and $7 \mathrm{a}^{\prime}-7 \mathrm{e}^{\prime}$. For comparison the corresponding spectra recorded without rf field are shown in Figs. 6a-6e and 7a-7e. As can be seen a complete rf collapse of the magnetic hyperfine structure to a quadrupole doublet is observed for both amorphous alloys (Figs. $6 a^{\prime}$ and $7 a^{\prime}$ ). The magnetic hyperfine field acting on the Mössbauer nuclei is averaged to zero because of the fast relaxation of the hyperfine field which results from the fast magnetization reversal induced by the external rf field. The rf field applied is sufficiently strong to overcome the magnetic anisotropy in the amorphous state. The switching time of magnetization reversal is short enough to enable the magnetization, and hence the hyperfine field to follow the external rf field oscillations, the frequency of which is about 3 times higher than the Larmor frequency. As a result of fast magnetization reversal the hyperfine field vanishes despite the fact that the sample remains in the ferromagnetic state, as evidenced by the presence of of side bands in the rf collapsed spectra. The side bands, related directly to magnetostriction, appear only in the ferromagnetic state $[43,46-51]$.

The characteristic features of the rf collapsed spectra remain almost unchanged as long as the alloys are in the amorphous state, i.e. when the annealing temperature does not exceed $500^{\circ} \mathrm{C}$ or $470^{\circ} \mathrm{C}$ for FeZrB and $\mathrm{FeZrBCu}$ alloys, respectively (Fig. $6 b^{\prime}$ ). The strong if side bands clearly seen in the rf collapsed spectrum of the as-quenched FeZrB alloy (Fig. 6a') markedly decrease for the sample annealed at $500^{\circ} \mathrm{C}$ (Fig. $6 \mathrm{~b}^{\prime}$ ), suggesting that the magnetostriction is reduced compared with that of the as-quenched alloy. 


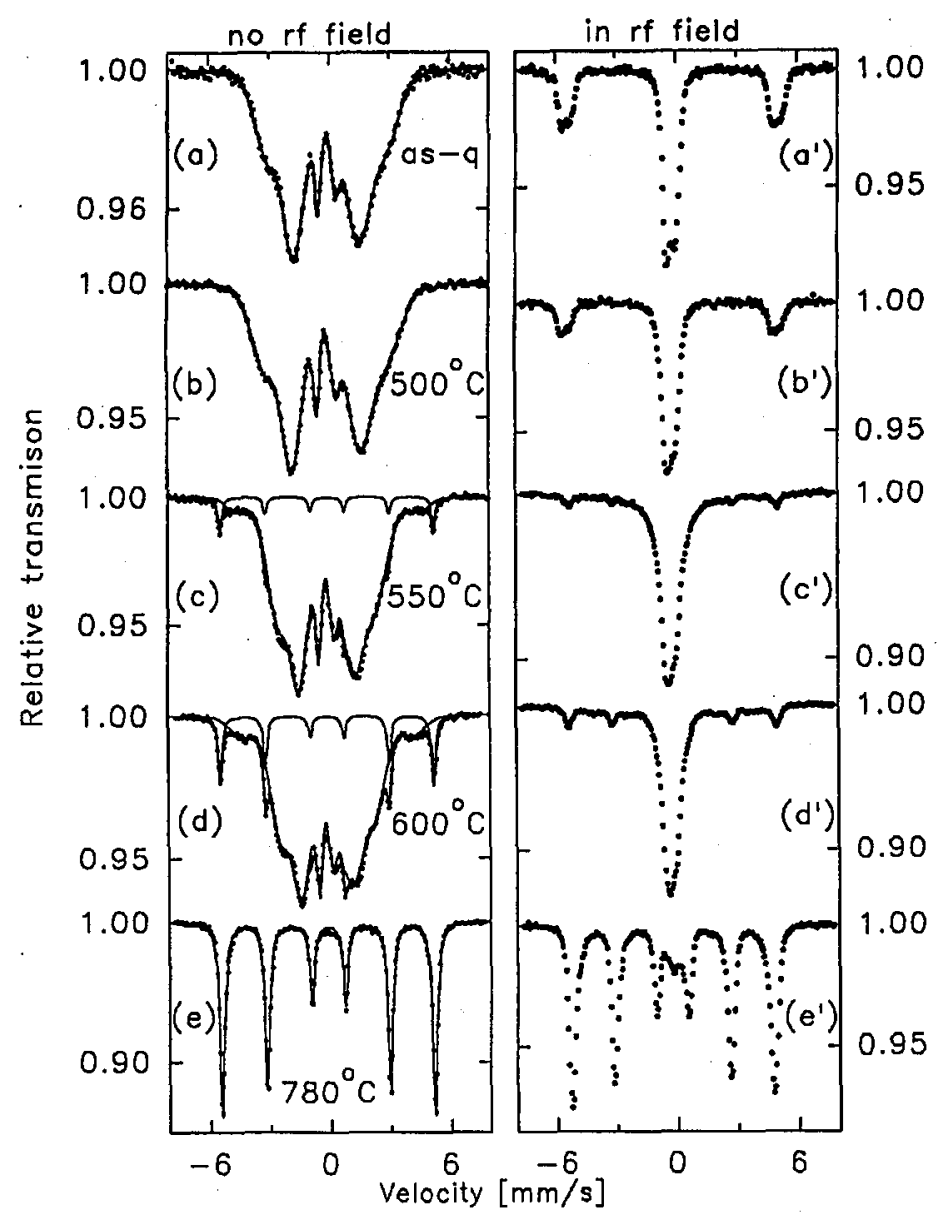

Fig. 6. The Mössbauer spectra recorded for the as-quenched and annealed $\mathrm{Fe}_{81} \mathrm{Zr}_{7} \mathrm{~B}_{12}$ alloy in the absence $(6 \mathrm{a})-(6 \mathrm{e})$ and during rf exposure $\left(6 \mathrm{a}^{\prime}\right)-\left(6 \mathrm{e}^{\prime}\right)$ to the field of $20 \mathrm{Oe}$ at $60.8 \mathrm{MHz}$.

The formation of the bcc-Fe phase causes a dramatic change of the shape of the rf collapsed spectra. The central collapsed part consists now of a superposition of a quadrupole doublet, corresponding to the retained amorphous matrix, and a single line which corresponds to the magnetically soft nanocrystalline bcc-Fe phase. This effect is clearly seen in Figs. $6 c^{\prime}$ and $7 b^{\prime}$. The rf side bands disappear completely in the case of the FeZrB alloy annealed at $550^{\circ} \mathrm{C}$ and $600^{\circ} \mathrm{C}$ (Figs. $6 \mathrm{c}^{\prime}-6 \mathrm{~d}^{\prime}$ ) and are strongly reduced for the $\mathrm{FeZrBCu}$ alloy annealed at $500^{\circ} \mathrm{C}\left(\right.$ Fig. $\left.7 \mathrm{~b}^{\prime}\right)$. This, together with the appearance of a single line in the collapsed spectra, gives strong evidence that the bcc-Fe phase appears in the form of nanoscale, magnetically soft and zero magnetostrictive grains. However, for the FeZrB alloy a noncollapsed component appears in addition to the fully collapsed spectral component; this noncollapsed component consists of a sextet with sharp lines and a hyperfine field and an isomer shift characteristic of the $\alpha$-Fe phase (Figs. $\left.6 c^{\prime}-6 d^{\prime}\right)$. This spectral 


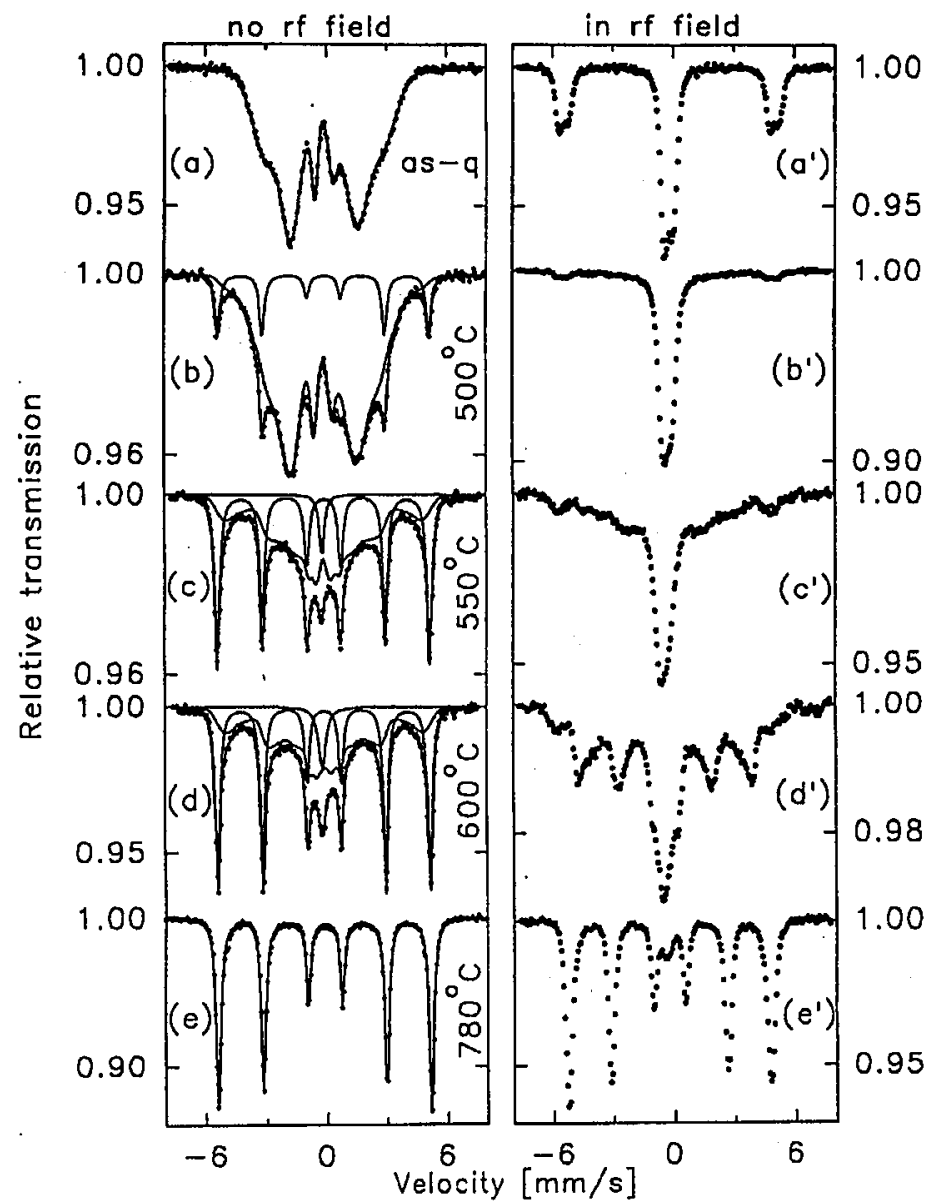

Fig. 7. The Mössbauer spectra recorded for the as-quenched and annealed $\mathrm{Fe}_{79} \mathrm{Zr}_{7} \mathrm{~B}_{12} \mathrm{Cu}_{2}$ alloy in the absence $(7 \mathrm{a})-(7 \mathrm{e})$ and during if exposure $\left(7 \mathrm{a}^{\prime}\right)-\left(7 \mathrm{e}^{\prime}\right)$ to the field of 20 Oe at $60.8 \mathrm{MHz}$.

component corresponds to the $\alpha$-Fe phase formed due to annealing of the $\mathrm{FeZrB}$ alloy at $550-600^{\circ} \mathrm{C}$ with larger, microcrystalline grains that have sufficiently high magnetic anisotropy to prevent the rf collapse. Thus, by using the rf induced effects it is possible to distinguish the magnetically soft nanoscale Fe grains from the magnetically harder microcrystalline grains of $\alpha$-Fe. This is not possible in the conventional Mössbauer measurements in which all Fe grains give a common contribution to the spectrum, regardless of their grain size and magnetic properties (anisotropy, magnetostriction) (Figs. 6c-6d). One can conclude that in the case of the $\mathrm{FeZrB}$ alloy annealing at $550-600^{\circ} \mathrm{C}$ causes the formation of $\mathrm{Fe}$ grains with two quite different sizes. In the completely crystallized FeZrB alloy (Fig. 6e) the rf effects cannot be induced. The magnetic anisotropy of the microcrystalline $\mathrm{Fe}$ phase is sufficiently large to prevent the external 20 Oe rf field from producing the reversal of magnetization; the rf collapse is completely suppressed. The spec- 
trum recorded during if exposure of the microcrystalline FeZrB sample (Fig. 6e') consists of a noncollapsed six-line component corresponding to magnetically hard $\alpha$-Fe.

In the case of the $\mathrm{FeZr} \cdot \mathrm{BCu}$ alloy the size distribution of the bcc $\mathrm{Fe}$ grains formed by annealing at $550-600^{\circ} \mathrm{C}$ differs considerably from that observed for the $\mathrm{FeZrB}$ alloy. The increase in the annealing temperature above $500^{\circ} \mathrm{C}$ and the corresponding increase in the amount of bcc-Fe grains, observed in Figs. 7c-7d, causes a dramatic change in the if collapsed spectra (Figs. $7 c^{\prime}-7 d^{\prime}$ ). The component revealing the unresolved partially collapsed hyperfine structure appears beside the fully collapsed components (QS doublet and single line) (Fig. $7 \mathrm{c}^{\prime}$ ). This is an evidence of the formation of grains with sufficiently large magnetic anisotropy to prevent the rf collapse (noncollapsed component) in addition to the magnetically very soft nanocrystalline grains of $\mathrm{Fe}$ for which a complete rf collapse is observed. The shape of the noncollapsed component changes from partially collapsed (at $550^{\circ} \mathrm{C}$, Fig. $\left.7 \mathrm{c}^{\prime}\right)$ to one consisting of a broadened but already well resolved sextet (at $600^{\circ} \mathrm{C}$, Fig. $7 \mathrm{~d}^{\prime}$ ), suggesting that in this alloy annealing causes the formation of grains with a broader distribution of anisotropy fields as related to the size distribution of bcc-Fe grains, embedded in the amorphous matrix, in clear distinction to the $\mathrm{FeZr} \cdot \mathrm{B}$ case discussed above. More information regarding the distribution of anisotropy fields is obtained from the study of the dependence of the rf collapse effect on the rf field intensity, discussed below.

Amnealing the $\mathrm{FeZrBCu}$ alloy at $780^{\circ} \mathrm{C}$ causes a final crystallization, as seen in Fig. 7e, and results in a complete suppression of the rf collapse (Fig. $7 \mathrm{e}^{\prime}$ ).

The Mössbauer measurements performed as a function of the rf field intensity for all $\mathrm{FeZrB}(\mathrm{Cu})$ alloys studied provide detailed information concerning the anisotropy fields. An example is shown in Fig. 8 for the $\mathrm{Fe}_{83} \mathrm{Zr}_{7} \mathrm{~B}_{8} \mathrm{Cu}_{2}$ alloy in the as-quenched state (Figs. 8a-8e) and after annealing at $500^{\circ} \mathrm{C}$ (Figs. $8 \mathrm{a}^{\prime}-8 \mathrm{e}^{\prime}$ ) and $550^{\circ} \mathrm{C}$ (Figs. $8 \mathrm{a}^{\prime \prime}-8 \mathrm{e}^{\prime \prime}$ ). As can be seen from Figs. 8a-8d the amorphous as-quenched alloy is magnetically very soft, therefore the decrease in the rf field intensity from 20 Oe to 6 Oe does not markedly affect the shape of the rf-collapsed spectrum. The collapsed spectrum broadens significantly at about 4 Oe (Fig. 8e). This shows that in the case of the as-quenched alloy the rf field of about $4 \mathrm{Oe}$, which starts to suppress the rf collapse effect, is comparable to the effective anisotropy field. The if side bands intensities decrease with decreasing of field intensity, as expected from the frequency modulation (FM) model of rf side bands effect [49].

For the sample annealed at $500^{\circ} \mathrm{C}$ the rf-collapsed spectrum contains, in addition to the fully collapsed central component, partially resolved broadened six-line component (Fig. 8a'). The decrease in the rf field intensity from 20 Oe to 12 Oe does not affect significantly the central collapsed component. However, the

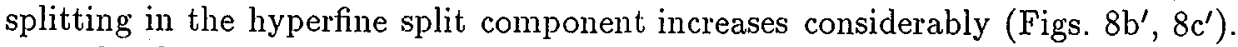
At 6 Oe the central collapsed component broadens and its spectral contribution decreases (Fig. 8d'). Further decrease in the rf field intensity results in a dramatic suppression of the rf collapse effect and in the increase in the spectral contribution of the noncollapsed six-line component whose splitting becomes similar to that characteristic of the microcrystalline $\alpha$-Fe phase (Fig. $8 \mathrm{e}^{\prime}$ ). 


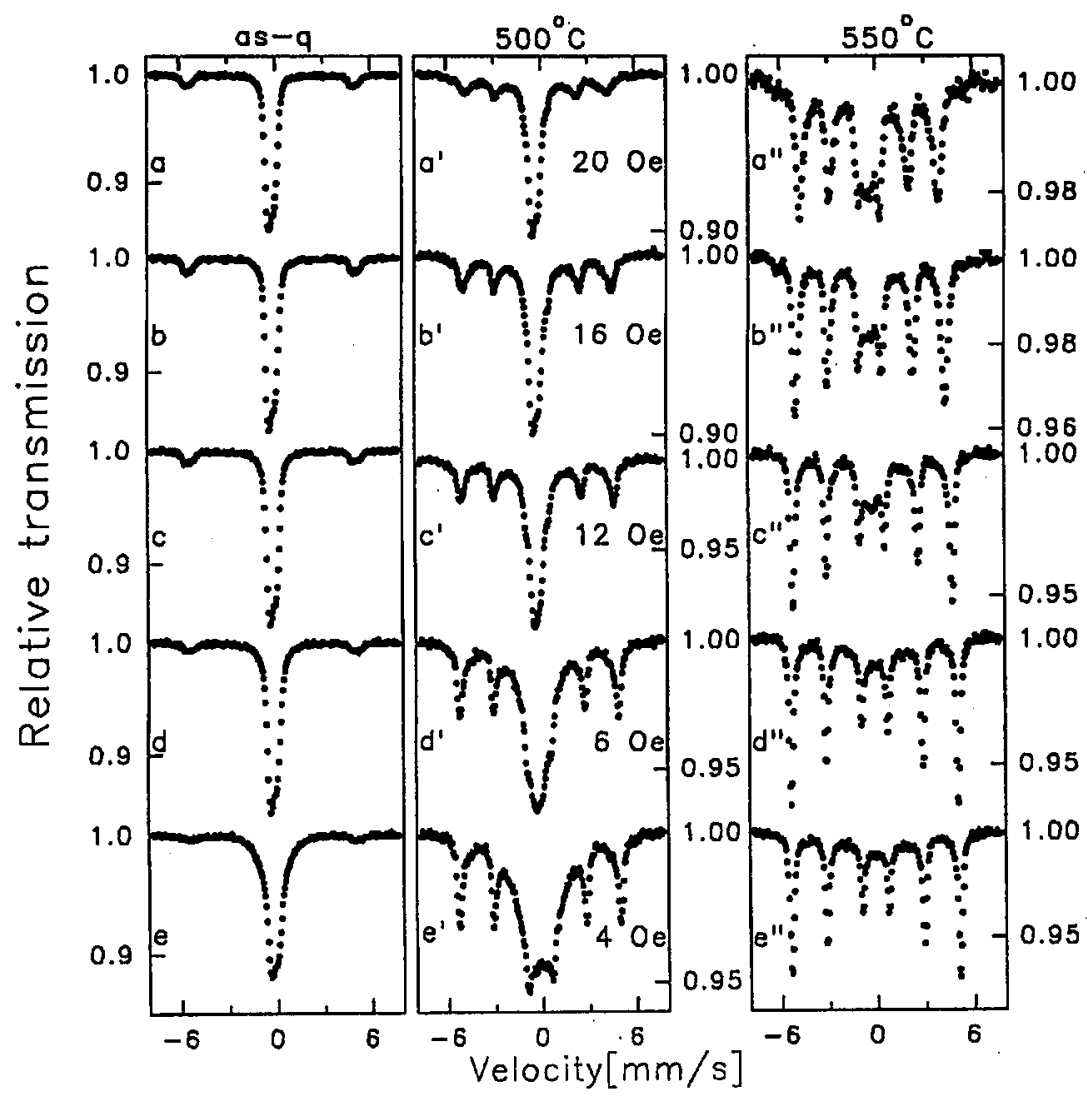

Fig. 8. The Mössbauer spectra recorded as a function of the rf field intensity for the as-quenched (a)-(e) and annealed at $500^{\circ} \mathrm{C}\left(\mathrm{a}^{\prime}\right)-\left(\mathrm{e}^{\prime}\right)$ and $550^{\circ} \mathrm{C}\left(\mathrm{a}^{\prime \prime}\right)-\left(\mathrm{e}^{\prime \prime}\right) \mathrm{Fe}_{83} \mathrm{Zr}_{7} \mathrm{~B}_{8} \mathrm{Cu}_{2}$ alloy.

A similar behaviour is observed in Figs. $8 \mathrm{a}^{\prime \prime}-8 \mathrm{e}^{\prime \prime}$ for the sample annealed at $550^{\circ} \mathrm{C}$. Here, the strongest rf field applied $\left(20\right.$ Oe, Fig. $\left.8 a^{\prime \prime}\right)$ is unable to induce complete collapse of the hyperfine structure. The spectrum consists of a central collapsed component related to the retained amorphous phase and the dominating magnetically split six-line component which is only slightly narrowed due to the rf field. As before, a decrease in the rf field intensity causes a suppression of the $\mathrm{rf}$ collapse effect and the central collapsed component disappears (Figs. 8a" $-8 \mathrm{~d}^{\prime \prime}$ ). At 4 Oe the splitting of the noncollapsed component approaches that characteristic of the $\alpha$-Fe phase (Fig. $8 \mathrm{e}^{\prime \prime}$ ). Since the rf collapse effect is very sensitive to the local magnetic anisotropy, the gradual suppression of the rf collapse effect and the increase in the splitting of the hyperfine split component as well as the increase in its spectral contribution with decreasing rf field intensity are related to the fact that the relation between the rf field intensity and anisotropy field is changing. For smaller rf fields the grains with a given magnetic anisotropy, which at larger rf field intensity contributed to the collapsed part of the spectrum, now contribute to the noncollapsed part. By changing the if field intensity one can use the rf 
collapse effect to "scan" the distribution of the anisotropy fields and to obtain more complete information about the distribution of the anisotropy fields and hence the grain size.

Thus the spectra in Fig. 8 provide evidence for the distribution of anisotropy fields and hence for the size distribution of the bcc-Fe grains. It is evident that the bcc-Fe phase has a larger magnetic anisotropy than the amorphous precursor. The nanocrystalline phase formed due to annealing at $500^{\circ} \mathrm{C}$ is magnetically softer than that formed at $T_{\mathrm{A}}=550^{\circ} \mathrm{C}$. As can be seen by comparing Figs. $8 \mathrm{a}^{\prime}-8 \mathrm{e}^{\prime}$ and $8 \mathrm{a}^{\prime \prime}-8 \mathrm{e}^{\prime \prime}$ the collapsed pattern dominates in the spectra of the alloy annealed at $500^{\circ} \mathrm{C}$ (Figs. $8 \mathrm{a}^{\prime}-8 \mathrm{e}^{\prime}$ ) while in those recorded for the sample annealed at $550^{\circ} \mathrm{C}$ the hyperfine split component is prevailing (Figs. $8 \mathrm{a}^{\prime \prime}-8 \mathrm{e}^{\prime \prime}$ ). The spectral contribution due to the rf collapsed component, clearly seen in Fig. $8 \mathrm{a}^{\prime \prime}$, decreases markedly with the lowering of the rf field intensity and vanishes at $H_{\mathrm{rf}} \approx 6$ Oe (Fig. $8 \mathrm{~d}^{\prime \prime}$ ). Thus the bcc-Fe grains formed at $T_{\mathrm{A}}=550^{\circ} \mathrm{C}$ reveal larger magnetic anisotropy and hence have larger average size than those formed at $T_{\mathrm{A}}=500^{\circ} \mathrm{C}$ in agreement with our XRD results [31]. The distributions of the size of the bec grains formed at both $T_{\mathrm{A}}$ temperatures are fairly broad and continuous as suggested by the continuous changes in the shape of the of spectra with rf field intensity.

Recently the rf-Mössbauer technique was used for studying the magnetic properties of $\mathrm{Fe}_{73.5} \mathrm{Nb}_{4.5} \mathrm{Cr}_{5} \mathrm{Cu}_{1} \mathrm{~B}_{16}$ nanocrystalline alloy [54] revealing similar effects to those discussed above. The nanocrystalline phase was produced in other iron-based ternary alloys such as $\mathrm{Fe}_{80} \mathrm{Ti}_{7} \mathrm{~B}_{12} \mathrm{Cu}_{1}$ [55] and $\mathrm{Fe}_{80} \mathrm{Nb}_{7} \mathrm{~B}_{12} \mathrm{Cu}_{1}$ [56]. Also in these cases the rf-Mössbauer technique proved to be a unique method for studying the magnetic anisotropy in each phase of the composite nanocrystalline alloy.

The details of the crystallization process in amorphous $\mathrm{FeZrB}(\mathrm{Cu})$ alloys were studied using the conversion electron Mössbauer spectroscopy [57]. Clear differences in the surface and bulk crystallization behaviours were detected. Not only the surface crystallization starts at lower annealing temperature than the bulk one, but additional phases were detected at the surface which do not form in the bulk. The enhanced surface crystallization was attributed to the boron depletion of the surface region which leads to the decrease in the crystallization temperature at the surface. The kinetics of crystallization of the $\mathrm{Fe}_{81} \mathrm{Zr}_{7} \mathrm{~B}_{12}$ alloy was studied by conventional, rf-Mössbauer and CEMS techniques [58].

In all these studies the Mössbauer spectroscopy appeared as an unrivalled method for studying the structure and magnetic properties of these novel, nanostructured soft magnetic alloys.

\section{Conclusions}

A detailed Mössbauer study of the $\mathrm{Fe} \mathrm{ZrB}(\mathrm{Cu})$ nanocrystalline alloys discussed above allowed us to draw the following conclusions:

(1) in all $\mathrm{FeZrB}(\mathrm{Cu})$ alloys the bcc-Fe phase is formed due to annealing. This result is fully supported by the XRD data. The increase in boron content in the alloys increases the crystallization temperature resulting in the enhanced thermal stability of the amorphous phase. The relative abundance of the bcc-Fe phase increases with decreasing boron content. The presence of $\mathrm{Cu}$ in alloys with 
the same boron content decreases the crystallization temperature and dramatically promotes the precipitation of the bcc-Fe phase;

(2) a complete rf collapse effect is observed only in fully-amorphous alloys. The rf-Mössbauer spectra consist of the fully collapsed component (QS doublet) accompanied by the rf side bands; the rf side bands, clearly seen for the as-quenched amorphous alloys, nearly disappear due to the formation of the nanocrystalline phase. This is related to the reduction of magnetostriction;

(3) the onset of the bcc-Fe phase affects the shape of the rf collapsed spectra; in addition to the QS doublet a single line appears. The noncollapsed six-line spectral component ( $H_{\mathrm{hf}}$ about $33 \mathrm{~T}$ ) appears in the rf spectra of alloys without $\mathrm{Cu}$ implying that a bimodal distribution of the bcc-Fe grain size appears at the early stage of crystallization;

(4) addition of $\mathrm{Cu}$ leads to a more homogeneous size distribution of bcc- $\mathrm{Fe}$ grains. However, the anisotropy of the nanocrystals is higher than that of the amorphous phase. The if collapse is not complete so the partly narrowed magnetic hyperfine split pattern appears in the spectra recorded during rf exposure;

(5) the spectral contribution of the partly narrowed hyperfine structure of the nanocrystalline bcc-Fe phase increases, at a given annealing temperature, with decreasing boron content in $\mathrm{Cu}$-containing alloys;

(6) the nanoscale bcc-Fe grains are smaller (lower anisotropy) in the $\mathrm{Cu}$-containing alloys with the same boron content. The relevant rf-Mössbauer spectra show larger spectral contribution of the rf collapsed component (despite the fact that the abundance of the retained amorphous phase is lower) and stronger narrowing of the noncollapsed hyperfine split component.

The unconventional if-Mössbauer technique, in which the rf collapse and side band effects are employed, permits us to distinguish the magnetically soft nanocrystalline bcc-Fe phase from the magnetically harder microcrystalline $\alpha-\mathrm{Fe}$ and provides information concerning the distribution of anisotropy fields related to the distribution of the size of the bcc-Fe grains. Thus this technique is superior to the conventional Mössbauer experiments which allow only the identification and determination of the relative abundance of the phases present in the material.

Qualitative information concerning the distribution of anisotropy fields related to the distribution of the size of the bcc-Fe grains can be inferred from the dependence of the rf collapsed spectra on the if field intensity. The rf-Mössbauer results show that the nanocrystalline bcc-Fe phase, being rnagnetically very soft, however has markedly larger anisotropy than that of the parent amorphous phase. The rf-Mössbauer technique provides a unique set of information on the microstructure and magnetic properties, particularly when combined with other techniques, such as XRD and SAXS, which allow direct estimation of the size of the nanoscale bcc-Fe grains.

\section{Acknowledgment}

The financial support from the grant no. 2 P03B 06815 from the Committee for Scientific Research is gratefully acknowledged. 


\section{References}

[1] Y. Yoshizawa, S. Ovum, K. Yamauchi, J. Appl. Phys. 64, 6044 (1988).

[2] G. Herzer, IEEE Trans. Magn. 26, 1397 (1990).

[3] G. Herzer, Mater. Sci. Eng. A 133, 1 (1991).

[4] Y. Yoshizawa, Y. Bizen, S. Arakawa, Mater. Sci. Eng. A 181/182, 871 (1994).

[5] M.L. Sui, K.Y. He, L.Y. Xiong, Y. Lin, J. Zhu, Mater. Sci. Eng. A 181/182, 1405 (1994).

[6] I. Skorvánek, R. Gerling, J. Appl. Phys. 72, 3417 (1992).

[7] P. Allia, M. Baricco, P. Tiberto, F. Vinai, J. Appl. Phys. 74, 3137 (1993).

[8] T. Kulik, A. Hernando, M. Vazquez, J. Magn. Magn. Mater. 133, 310 (1994).

[9] K. Suzuki, A. Makino, N. Kataoka, A. Inoue, T. Masumoto, Mater. Trans. Jpn. Inst. Met. 32, 93 (1991).

[10] K. Suzuki, A. Makino, A. Inoue, T. Masumoto, J. Appl. Phys. 74, 3316 (1993).

[11] K. Suzuki, A. Makino, A. Inoue, T. Masumoto, J. Appl. Phys. 70, 6232 (1991).

[12] K. Suzuki, A. Makino, A.P. Tsai, A. Inoue, T. Masumoto, Mater. Sci. Eng. A 179/180, 501 (1994).

[13] K.Y. Kim, T.H. Noh, I.K. Kang, Mater. Sci. Eng. A 179/180, 552 (1994).

[14] A. Makino, T. Hatanai, A. Inoue, T. Masumoto, Mater. Sci. Eng. A 226-228, 594 (1997).

[15] A. Makino, T. Hatanai, Y. Naitoh, T. Bitoh, A. Inoue, T. Masumoto, IEEE Trans. Magn. 33, 3793 (1997).

[16] N. Kataoka, M. Hosokawa, A. Inoue, T. Masumoto, Jpn. J. Appl. Phys. 28, L262 (1989).

[17] R. Alben, J.J. Becker, M.C. Chi, J. Appl. Phys. 49, 1653 (1978).

[18] A. Hernando, M. Vazquez, T. Kulik, C. Prados, Phys. Rev. B 51, 3581 (1995).

[19] C. Gomez-Polo, D. Holzer, M. Multigner, E. Navarro, P. Agudo, A. Hernando, M. Vazquez, H. Sassik, R. Grössinger, Phys. Rev. B 53, 3392 (1996).

[20] G. Hampel, A. Pundt, J. Hesse, J. Phys., Condens. Matter 4, 3195 (1992).

[21] A. Pundt, G. Hampel, J. Hesse, Z. Phys. B, Condens. Matter 87, 65 (1992).

[22] X.Z. Zhou, A.H. Morrish, D.G. Naugle, R. Pan, J. Appl. Phys. 73, 6597 (1993).

[23] A. Cserei, J. Jiang, F. Aubertin, U. Gonser, J. Mater. Sci. 29, 1213 (1994).

[24] M. Miglierini, J. Phys., Condens. Matter 6, 1431 (1994).

[25] T. Pradell, N. Clavaguera, J. Zhu, M.T. Clavaguera-Mora, J. Phys., Condens. Matter 7, 4129 (1995).

[26] P. Duhaj, I. Matko, P. Švec, J. Sitek, D. Janičkovič, Mater. Sci. Eng. B 39, 208 (1996).

[27] M. Kopcewicz, A. Grabias, P. Nowicki, J. Magn. Magn. Mater. 140-144, 461 (1995).

[28] C.S. Kim, S.B. Kim, J.S. Lee, T.H. Noh, J. Appl. Phys. 79, 5459 (1996).

[29] M. Miglierini, J.M. Greneche, J. Phys., Condens. Matter 9, 2303 (1997).

[30] M. Miglierini, J.M. Greneche, J. Phys., Condens. Matter 9, 2321 (1997). 
[31] M. Kopcewicz, A. Grabias, P. Nowicki, D.L. Williamson, J. Appl. Phys. 79, 993 (1996).

[32] M. Kopcewicz, A. Grabias, D.L. Williamson, J. Appl. Phys. 82, 1747 (1997).

[33] M. Kopcewicz, A. Grabias, P. Nowicki, Mater. Sci. Eng. A 226-228, 515 (1997).

[34] T. Graf, M. Kopcewicz, J. Hesse, J. Phys., Condens. Matter 8, 3897 (1996).

[35] M. Kopcewicz, J. Jagielski, T. Graf, M. Fricke, J. Hesse, Hyperfine Interact. 94, 2223 (1994).

[36] M. Kopcewicz, A. Grabias, P. Nowicki, Nanostructured Mater. 6, 957 (1995).

[37] M. Kopcewicz, A. Grabias, P. Nowicki, Mater. Res. Soc. Symp. Proc. 384, 517 (1995).

[38] R.A. Brand, J. Lauer, D.M. Herlach, J. Phys. F 13, 675 (1983).

[39] J. Hesse, A. Rübartsch, J. Phys. E 7, 526 (1974).

[40] G. LèCaer, J.M. Dubois, J. Phys. E 12, 1083 (1979).

[41] M. Oguchi, Y. Harakawa, A. Inoue, T. Masumoto, K. Suzuki, J. Mater. Sci. 29, 1825 (1994).

[42] H. Kobayashi, H. Onodera, H. Yamamoto, J. Phys. Soc. Jpn. 55, 331 (1986).

[43] L. Pfeiffer, in: Mössbauer Effect Methodology, Vol. 7, Ed. I.J. Gruvermann, Plenum Press, New York 1972, p. 263.

[44] G. Albanese, G. Asti, S. Rinaldi, Nuovo Cimento B 6, 153 (1971).

[45] M. Kopcewicz, Phys. Status Solidi A 46, 675 (1978).

[46] L. Pfeiffer, N.D. Heiman, J.C. Walker, Phys. Rev. B 6, 74 (1972).

[47] G. Asti, G. Albanese, C. Bucci, Phys. Rev. 184, 260 (1969).

[48] M. Kopcewicz, A. Kotlicki, M. Szefer, Phys. Status Solidi B 72, 701 (1975).

[49] M. Kopcewicz, in: Mössbauer Spectroscopy Applied to Inorganic Chemistry, Vol. 3, Eds. G.J. Long, F. Grandjean, Plenum Press, New York 1989, p. 243.

[50] M. Kopcewicz, Structural Chem. 2, 313, (1991).

[51] J.K. Srivastava, in: Advances in Mössbauer Spectroscopy, Eds. B.V. Thosar, P.K. Iyengar, J.K. Srivastava, S.C. Bhargava, Elsevier, Amsterdam 1983, p. 761.

[52] T. Graf, M. Kopcewicz, J. Hesse, J. Magn. Magn. Mater. 140-144, 423 (1995).

[53] T. Graf, M. Kopcewicz, J. Hesse, Nanostructured Mater. 6, 937 (1995).

[54] M. Kopcewicz, A. Grabias, I. Škorvánek, J. Appl. Phys. 83, 935 (1998).

[55] M. Kopcewicz, A. Grabias, B. Idzikowski, J. Magn. Magn. Mater. 177-181, 1434 (1998).

[56] M. Miglierini, M. Kopcewicz, B. Idzikowski, Z.E. Horváth, A. Grabias, I. Skorvánek, P. Dłużewski, Cs.S. Daróczi, J. Appl. Phys., in print.

[57] M. Kopcewicz, A. Grabias, J. Appl. Phys. 80, 3422 (1996).

[58] A. Grabias, M. Kopcewicz, Mater. Sci. Forum 269-272, 725 (1998). 